\title{
Further Investigation of Distinct Components of Stroop Interference and of their Reduction by Short Response-Stimulus Intervals
}

\author{
Maria Augustinova ${ }^{1,2}$, Laetitia Silvert ${ }^{1}$, Nicolas Spatola ${ }^{1}$ and Ludovic Ferrand ${ }^{1}$ \\ ${ }^{1}$ Université Clermont Auvergne, CNRS, LAPSCO, F-63000 Clermont-Ferrand, France \\ ${ }^{2}$ Université de Rouen, France
}

Running head: The reduction of distinct components of Stroop interference by short RSIs.

Type of article: regular paper (Special Issue)

\section{Contact address:}

Maria Augustinova or Ludovic Ferrand

CNRS and University Blaise Pascal

Laboratoire de Psychologie Sociale et Cognitive (LAPSCO - UMR CNRS 6024)

34, avenue Carnot

63037 Clermont-Ferrand

FRANCE

E-mail: maria.augustinova@univ-rouen.fr ludovic.ferrand@univ-bpclermont.fr;

Phone: + 33473406257

Fax: + 33473406114 


\begin{abstract}
The aim of this paper is to extend the so-called semantic Stroop paradigm (Neely \& Kahan, 2001) - which already successfully distinguishes between the contribution of the semantic vs. response conflict to Stroop interference - so that it can take account of and capture the separate contribution of task conflict. In line with this idea, the Stroop interference observed using the aforementioned paradigm with both short and long RSIs (500 vs. $2000 \mathrm{ms)}$ did indeed reflect the specific contribution of the task, semantic and response conflicts. However, the contribution of task conflict (as opposed to the semantic and response conflicts) failed to reach significance when the semantic Stroop paradigm was administered with manual (Experiment 1) as opposed to vocal responses (Experiment 2). These experiments further tested the extent to which the specific contribution of the different conflicts can be influenced by the increased cognitive control induced by a short (vs. long) RSI. The corresponding empirical evidence runs contrary to the assumption that the reduction of overall Stroop interference by a short (vs. long) RSI is due to the reduced contribution of the task (Parris, 2014) and/or semantic (De Jong, Berendsen, \& Cools, 1999) conflicts. Indeed, in neither experiment was the contribution of these conflicts reduced by a short RSI. In both experiments, this manipulation only reduced the contribution of the response conflict to the overall Stroop interference (e.g., Augustinova \& Ferrand, 2014b). Thus these different results clearly indicate that Stroop interference is a composite phenomenon involving both automatic and controlled processes. The somewhat obvious conclusion of this paper is that these processes are more successfully integrated within multi-stage accounts than within the historically favored single-stage response competition accounts that still dominate current psychological research and practice.
\end{abstract}


Key words: Stroop interference, Response-Stimulus Interval duration, Task conflict, Semantic conflict, Response conflict 


\section{Introduction}

The Stroop task (Stroop, 1935) requires individuals to identify, as quickly and accurately as possible, the font color of written characters without reading them. Despite this requirement, the typical result is that individuals' identification times are longer and more error-prone for color-incongruent Stroop words (i.e., words displayed in a color that is different from the one they designate such as "BLUE" displayed in green ink; hereafter $B L U E_{\text {green }}$ ), than for color-neutral items (e.g., "DOG"/ "XXX" displayed in green ink, $\left.D O G / X X X_{\text {green }}\right)$

This difference - called Stroop interference - is often thought to result from the socalled response conflict (e.g., MacLeod, 1991; MacLeod \& MacDonald, 2000) present in the aforementioned color-incongruent Stroop words (e.g. $\left.B L U E_{\text {green }}\right)$. This conflict is thought to arise because word reading is routinized through practice. Consequently, the irrelevant word dimension of these words (i.e., blue for $B L U E_{\text {green }}$ ) provides evidence toward a response that is thought to interfere with the one cued by the relevant color dimension (i.e., green here).

This latter consideration - which is shared by so-called single-stage response competition accounts (see e.g., Risko, Schmidt \& Besner, 2006 for this terminology) contrasts with the results of several more recent lines of research. These lines of research that have given rise to what is termed multi-stage accounts (Risko et al., 2006) - suggest that Stroop interference is a more complex phenomenon that goes beyond a single (i.e., response) conflict depicted above. Currently however, these accounts diverge with regard to the types of conflicts involved in Stroop interference. Thus the present paper addresses just this issue.

\subsection{Which types of conflicts does Stroop interference actually involve?}

The single-stage response competition accounts (also called late-selection accounts) have historically been favored in the Stroop literature, first over so-called early-selection 
accounts (e.g., Logan \& Zbrodoff, 1998; MacLeod, 1991; Risko et al., 2006). These other kinds of single-stage accounts share the idea that Stroop interference results solely from a conflict that occurs much earlier in processing than the aforementioned response conflict ${ }^{1}$.

Seymour (1977) considers for instance that this semantic conflict occurs precisely at conceptual encoding of color-incongruent words (e.g. $\left.B L U E_{\text {green }}\right)$. In this view, “(...) delays of processing occur whenever distinct semantic codes are simultaneously activated, and that these delays become acute when the conflicting codes are values on a single dimension or a closely related dimensions." (Seymour, 1977, p. 263; see also e.g. Luo, 1999; Scheibe, Shaver, \& Carrier, 1967; Seymour, 1974; 1977; Stirling, 1979). In sum, this conflict occurs in the amodal semantic network because the meaning of the word dimension and that of the color dimension both correspond to colors.

The first systematic conceptualization of multi-stage processing in the Stroop task arose specifically from a critique of the opposition between early and late-selection accounts. Specifically, Zang and Kornblum (1998) point to the fact that "These two proposals (...) focus on one particular aspect of the Stroop task to the exclusion of the other. The early-selection account focuses on the similarity between the relevant stimulus and the irrelevant stimulus, whereas the late-selection account focuses on the similarity between the irrelevant stimulus and the response. Both similarity relationships are, of course, present in the Stroop task - in fact, they constitute a confounding that makes distinguishing empirically between the two accounts difficult." (p. 4).

It is thus not surprising that later multi-stage accounts assumed the existence of both stimulus and response conflicts (e.g., Augustinova \& Ferrand, 2014b, De Houwer, 2003a, Manwell, Roberts, \& Besner, 2004; Neely \& Kahan, 2001; Schmidt \& Cheesman, 2005;

\footnotetext{
${ }^{1}$ This conflict is usually referred to as stimulus conflict - a term that is rather agnostic with respect to its underlying processes. Indeed, some early-selection accounts posit that these processes are perceptual (e.g., Hock \& Egeth, 1970), some others that they are conceptual (i.e., semantic, Seymour, 1977) in their nature. Given that this paper subsequently focuses on this latter view, we only introduce the idea of semantic conflict (but see e.g. MacLeod, 1991 for a complete view of this issue).
} 
Zhang \& Kornblum, 1998; see also e.g., Augustinova et al., 2015; Chen, Lei, Ding, Li, \& Chen, 2013; Killikelly \& Szücs, 2013; Szücs \& Soltész, 2010; Van Veen \& Carter, 2005 for electrophysiological and fMRI evidence).

Several other multi-stage accounts also assume that Stroop interference results from the simultaneous contribution of two distinct conflicts. However, in addition to the response conflict, they assume the existence of so-called task conflict instead of the semantic conflict assumed by earlier accounts.

Task conflict is thought to arise because the individual's attention is drawn to the irrelevant (i.e., word reading) task instead of being fully focused on the relevant (i.e., color naming) task (e.g., Goldfarb \& Henik, 2006, 2007; Kalanthroff, Goldfarb, \& Henik, 2013; Kalanthroff, Goldfarb, Usher, \& Henik, 2013; MacLeod \& MacDonald, 2000; Monsell, Taylor \& Murphy, 2001; Parris, 2014; see also e.g., e.g., Bench, Frith, Grasby, Friston, Paulesu, Frackowiak, et al., 1993 for fMRI evidence).

For instance, Monsell and colleagues (2001) incorporated task and response conflicts in what they termed a two-factor account of Stroop interference. More specifically, they argued that " $(\ldots)$ when a stimulus affords multiple responses, as with a colored word, there may be two sources of interference with the performance of the weaker task, color naming. The first is competition at the level of whole task sets. (...) The second is competition from a specific response tendency, the word's name, activated in spite of the intended suppression of the reading task set.” (p. 149).

To sum up, both types of multi-stage accounts depicted above emphasize the contribution of two distinct conflicts to overall Stroop interference. The first type suggests that it results from semantic and response conflicts (hereafter SC-RC accounts) whereas the second type suggests that the overall Stroop interference results from task and response conflicts (hereafter TC-RC accounts). Given that the considerable empirical evidence points 
to the viability of each of them, the empirical work presented in this paper adopts the integrative assumption that all three conflicts - task, semantic and response conflicts expected by these accounts are specific in their nature and that they thus all contribute to standard (i.e., overall) Stroop interference. In line with this idea, the first empirical objective of this work is to examine the extent to which their distinct contribution can be reliably captured in the so-called semantic Stroop paradigm (see Neely \& Kahan, 2001 for the initial theoretical impetus, and e.g., Augustinova \& Ferrand, 2014ab for the review of later empirical implementations).

\subsection{How to (potentially) capture task conflict in the semantic Stroop paradigm?}

In its current form, the semantic Stroop paradigm supplements standard colorincongruent (e.g., $B L U E_{\text {green }}$ ) and color-neutral (e.g., $\left.D O G_{\text {green }}\right)$ words that are commonly used in the standard Stroop paradigm with color-associated words (e.g., $S K Y$ displayed in green, hereafter $S K Y_{\text {green }}$ first introduced by Klein, 1964). This addition - initially suggested by Neely and Kahan (2001) - follows the aforementioned logic underlying SC-RC accounts. Such that it assumes the presence of semantic conflict in both associated and standard colorincongruent words and the presence of response conflict only in standard color-incongruent words.

Indeed, because the meaning activated by the irrelevant word dimension of both colorincongruent words (e.g., $B L U E_{\text {green }}$ and $S K Y_{\text {green }}$ ) corresponds to and/or is closely related to a color (blue here), it subsequently slows processing of the meaning that is activated by the color-dimension (e.g., green) of these words (see Seymour's reasoning about semantic conflict above). Inversely, because the meaning activated by the irrelevant word dimension of color-neutral words (e.g., dog for $D O G_{\text {green }}$ ) is not related to a color, these items are free of 
semantic conflict.

Additionally, once the irrelevant word dimension of standard color-incongruent words (e.g., $B L U E_{\text {green }}$ ) has been adequately processed, it primes a specific (pre-)response tendency that shares the same response set (hence interferes with) that the one primed by the meaning of the relevant color dimension (see e.g., Monsell and colleagues' reasoning about response conflict above). Inversely, because the word dimension of associated color-incongruent words (e.g., $S K Y_{\text {green }}$ ) does not activate (pre-)motor responses linked to the associated color (e.g., press a blue button on seeing $S K Y$; see Schmidt \& Cheesman, 2005 for a direct

demonstration), their response set does not overlap with that activated by the color-dimension. Consequently, associated color-incongruent words (e.g., $\left.S K Y_{\text {green }}\right)$ are, exactly like colorneutral ones $\left(D O G_{\text {green }}\right)$, free of response conflict (but see e.g., Hasshim \& Parris, 2014, 2015; Klein, 1964 for a different view).

In line with these assumptions, the semantic Stroop paradigm allows observing the delay in processing (i.e., interference) for both types of color-incongruent words compared to color-neutral ones with the magnitude of this interference being greater for standard as compared to associated color-incongruent words (e.g., Augustinova \& Ferrand, 2012a, 2012b, 2014a; Augustinova, Flaudias, \& Ferrand, 2010; Augustinova, Silvert, Ferrand, Llorca, \& Flaudias, 2015; Ferrand \& Augustinova, 2014, Manwell et al., 2004; Schmidt \& Cheesman, 2005, see also e.g., Risko et al., 2006; White et al., 2016).

Thus, contrary to TC-RC accounts and in line with SC-RC accounts, this evidence suggests that the contribution of semantic conflict (e.g., $S K Y_{\text {green }}-D O G_{\text {green }}$ ) to overall (i.e., standard) Stroop interference (e.g., $B L U E_{\text {green }}-D O G_{\text {green }}$ ) cannot be equated with the one of response conflict (e.g., $\left.B L U E_{\text {green }}-S K Y_{\text {green }}\right)$.

Conversely, and in line with TC-RC accounts, the semantic conflict cannot be equated with the task conflict. Indeed, the semantic Stroop paradigm shares the fundamental 
assumption of the TC-RC accounts, namely that the irrelevant reading task (which results in task conflict) is activated for all of the words used in this paradigm (i.e., color-incongruent and color-neutral ones).

As a result, it specifically uses words (e.g., $D O G_{\text {blue }}$ ) and not other kinds of colorneutral baseline (e.g., $\left(\mathbf{\square} \mathbf{\square}_{\text {blue, }}{ }^{* * *}\right.$ blue, $D D D_{\text {blue }}, D E G_{\text {blue, }}$, see e.g., Manwell et al., 2004; Neely \& Kahan, 2001 for further discussions of this point). Given that the color-incongruent (e.g., $\left.S K Y_{\text {green }}, B L U E_{\text {green }}\right)$ and color-neutral words ( $D O G_{\text {green })}$ used by our research group to implement the semantic Stroop paradigm are more or less equal in their length and frequency (see also Method section), it seems reasonable to assume that the irrelevant reading task, hence the task conflict that it entails, remains constant across items.

Indeed, bi-modal, interactive activation model with (amodal) semantics (McClelland \& Rumelhart, 1981; McClelland, 1987; Grainger \& Ferrand, 1994, 1996; Grainger \& Holcomb, 2009) $)^{2}$ in which our implementation of the semantic Stroop paradigm is rooted, predicts in these conditions the same amount of orthographic, lexical and semantic processing.

Although the empirical objectives were different, our research group also implemented the semantic Stroop paradigm with a color-neutral baseline other than words. Augustinova and Ferrand (2014a) found, for instance, that the contribution of the semantic conflict to overall Stroop interference was of $92 \mathrm{~ms}$ when it was captured by the difference in mean RTs for associated color-incongruent words and color-neutral letter strings (e.g., $S K Y_{\text {green }}-$ $X X X_{\text {green }}$, Exp.2). The magnitude of this contribution dropped to $31 \mathrm{~ms}$ when estimated on the basis of the difference in mean RTs for associated color-incongruent and color-neutral words (e.g., $S K Y_{\text {green }}-D O G_{\text {green }}$, Exp.3).

\footnotetext{
${ }^{2}$ The architecture of the model is a hierarchical system that distinguishes separate featural, sublexical (smaller than words), and lexical and semantic (whole-word) levels of processing that take place in cascade. This model also assumes that the visual recognition of words (i.e., processing that starts with feature extraction and ends with semantic activation) can be neither prevented nor interrupted at any point and thus runs until completed (but see, e.g., Besner et al., 2016; Manwell et al., 2004 for a different view).
} 
Even though this observation comes from two separate experiments (see also Augustinova \& Ferrand, 2012b), it is consistent with the well-known fact that coloridentification is slower for color-neutral words than for other kinds of color-neutral baselines

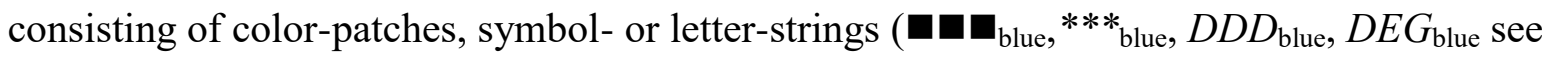
e.g., Brown, 2011; Fox, Schor, \& Steinman, 1971; Klein, 1964; MacLeod, 1991; Monsell et al., 2001).

It is also consistent with the aforementioned bi-modal interactive activation model. Indeed, it predicts that word-like stimuli (e.g., XXX) will be processed faster than words (e.g., DOG) because the irrelevant (i.e., word-reading) task activated by the former stops at the orthographic pre-lexical level, whereas the one activated by the latter stops with access to the meaning.

Thus, these different (empirical and theoretical) arguments independently point to the fact that the positive difference in mean response latencies between color-neutral words and letter-strings (e.g., $D O G_{\text {green }}-X X X X_{\text {green }}$ ) might provide a way of taking account of and capturing the specific behavioral expression of task conflict in the semantic Stroop paradigm. The two experiments presented below were designed to empirically address just this issue.

In addition to extending the semantic Stroop paradigm in such a way that it incorporates the task, semantic and response conflicts, all of which are assumed in certain of the SC-RC and TC-RC accounts, these two experiments also examined the related issue of the degree to which the specific contribution of these different conflicts is permeable to cognitive control induced by short response-stimulus intervals (De Jong, Berendsen, \& Cools, 1999). We discuss this issue in more detail in the following section.

\subsection{The influence of Short Response-Stimulus Intervals on the distinct components of Stroop interference}


Stroop interference is indeed traditionally considered to reflect cognitive control, with lower levels of Stroop interference reflecting greater control. Past research into the efficiency of this control has tried to identify the factors that allow individuals to maintain high levels of control across time.

One manipulation that seems to be particularly effective is to shorten the time that elapses between the individual's response and the presentation of a new stimulus on a computer screen (i.e., response-stimulus interval, hereafter RSI). Indeed, this intervention, which causes individuals to perform the task at a much faster rate than is ordinarily the case, considerably reduces the magnitude of Stroop interference (De Jong et al., 1999; Jackson \& Balota, 2013; Parris, 2014)

For instance, in a two-response spatial Stroop task (i.e., responding to the words "ABOVE" and "BELOW" presented either above or below the fixation point), as was used in the original study of De Jong and colleagues, the magnitude of the Stroop-like interference observed at a RSI of $2000 \mathrm{~ms}$ dropped from $47 \mathrm{~ms}$ to a non-significant $11 \mathrm{~ms}$ when a short RSI of 200 ms was used.

More recently, Parris (2014) extended the benefit of short RSIs to standard Stroop interference (i.e., the difference in mean RTs for color-incongruent and color-neutral Stroop words). In his study, the Stroop interference observed with manual responses fell from $45 \mathrm{~ms}$ with a long RSI of $3500 \mathrm{~ms}$ to a non-significant $15 \mathrm{~ms}$ with a short RSI of $200 \mathrm{~ms}$ (see also Jackson \& Balota, 2013).

However, if all previous studies agree on the fact that the reduction of Stroop interference with short (as compared to long) RSIs is due to the maintenance of the attentional focus across time on the relevant (i.e., color) dimension of Stroop words, they clearly disagree as to the types of conflict that benefit directly from this heightened attentional selectivity.

Subscribing to the TC-RC accounts described above, Parris argued that maintaining a 
consistent focus on the relevant color dimension across time causes a low task conflict, rather than an increased inhibition of word meaning as has been proposed by De Jong and colleagues. More precisely, Parris's reasoning is rooted in the assumption that the expected increase in proactive control (Braver, 2012) resulting from short RSIs has an early impact on the processing of Stroop words and thereby reduces task conflict (but see e.g., Levin \& Tzelgov, 2014).

In contrast, De Jong et al. (1999) originally reasoned that this control - which is enhanced by short RSIs - comes into play later (i.e., at the level of word processing). According to this reasoning, individuals are perfectly able to inhibit the irrelevant word dimension, but this capability is fully available to them only when their attention is intently focused on the relevant color dimension, as is the case with short RSIs.

As can be seen, if the initial proposal made by De Jong and colleagues (1999) is correct, semantic conflict should be reduced in certain circumstances, whereas the proposal of Parris (2014) would point to a reduced task conflict. It is important to note at this point that these selective effects have both been simply inferred from the reduction in overall Stroop inference (and from the boost in facilitation observed by Parris ${ }^{3}$ ). Thus, even though these lines of research raise an important question concerning the types of conflicts that are influenced by an increased focus on the relevant color-dimension (through the use of a short RSI), there is still no evidence enabling us to provide a direct answer to this question.

Related to this issue, and in line with the bi-modal interactive activation model with (amodal) semantics, Augustinova and Ferrand (2014b) have pointed out that the automaticity of semantic activation in the Stroop task (see also e.g., Neely \& Kahan, 2001; but see e.g., Besner et al., 2016) means that the detection of the semantic conflict (as opposed to its resolution) is also likely to be automatic. Even though this observation does not preclude the

\footnotetext{
${ }^{3}$ See Dalrymple-Alford (1972) and Dalrymple-Alford and Budayr (1966) for the first introduction of colorcongruent words and resulting facilitative effects in the Stroop task that are often misattributed to Stroop (1935).
} 
possibility that various moderators (such as the short RSIs mentioned above) may

successfully influence the resolution of this conflict, the extent to which this is indeed the case has not as yet been demonstrated.

This latter claim results from the finding that the various interventions known to reduce standard Stroop interference (e.g., single-letter coloring, see e.g., Besner, Stolz, \& Boutilier, 1997; or social priming of dyslexia, see e.g., Goldfarb, Aisenberg, \& Henik, 2011, to name just a few) have no influence on the magnitude of the semantic conflict observed in the semantic Stroop paradigm (see e.g., Augustinova \& Ferrand, 2007, 2012a, 2012b, 2014a; Augustinova et al., 2010; 2015; see also e.g. Augustinova \& Ferrand, 2014b, for a review). Instead, these interventions consistently reduce the magnitude of the response conflict, whose contribution to overall Stroop interference can thus be considered as (highly) controllable.

Consequently, and in just the same way as the various interventions described above, short RSIs (compared to long ones) might (also) be expected to reduce the contribution of the response conflict to Stroop interference. The two experiments described below were designed to test these different predictions directly.

\subsection{The Present Study}

The present study departs from an integrative assumption that the task, semantic and response conflicts - variously posited by the TC-RC and SC-RC accounts - constitute specific types of conflicts that all contribute to overall Stroop interference. Thus the first objective of this study was to empirically assess the extent to which these different contributions can reliably be captured using the extended version of the semantic Stroop paradigm.

To this end, in addition to the standard color-incongruent words (e.g., $B L U E_{\text {green }}$ ), associated color-incongruent words (e.g., $\left.S K Y_{\text {green }}\right)$ and color-neutral words (e.g., $\left.D O G_{\text {green }}\right)$ 
that are commonly used in the semantic Stroop paradigm, color-neutral letter-strings (e.g., $\left.X X X X_{\text {green }}\right)$ were also used in the present study. This operationalization assumes that task conflict is present for all these four types of items ${ }^{4}$. It further assumes the presence of semantic conflict in both associated and standard color-incongruent words and the presence of response conflict only in standard color-incongruent words.

Consequently, the positive difference in mean response latencies between color-neutral words and letter-strings (e.g., $D O G_{\text {green }}-X X X X_{\text {green, }}$, see Figure 1) was expected to capture the specific contribution of task conflict to overall Stroop interference (i.e., a contribution that is not intermixed with that of the semantic and response conflicts induced by colorincongruency involved in color-incongruent words).

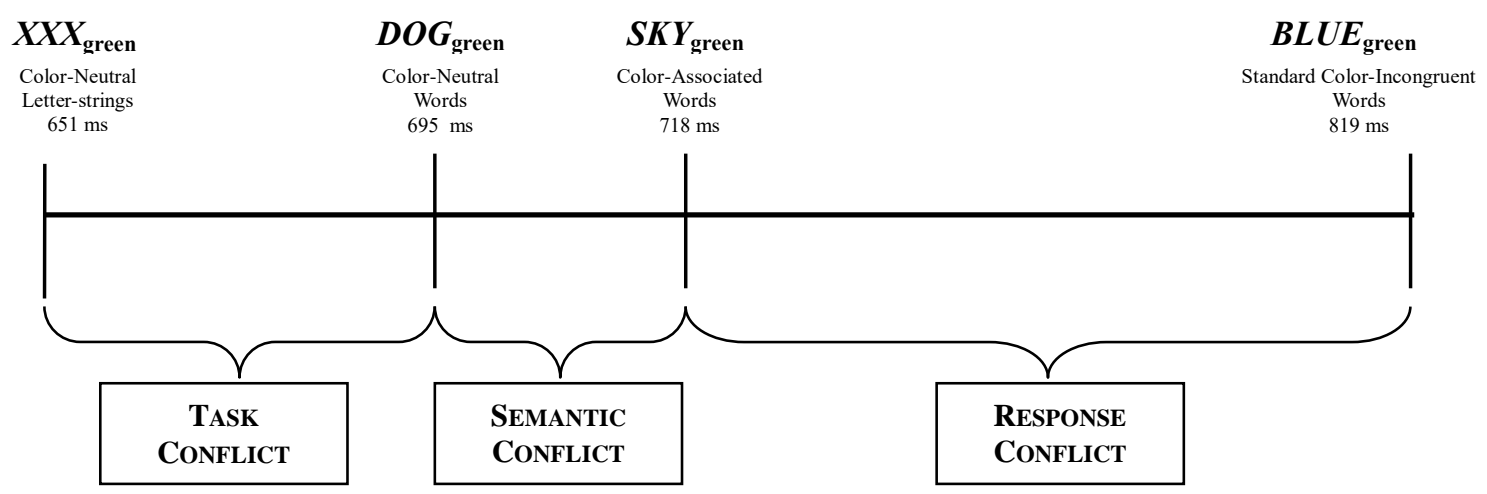

Figure 1. The subtractive logic of the extended semantic Stroop interference (see e.g., Augustinova \& Ferrand, 2014b; Manwell et al., 2004) applied to the data from a vocal naming task (Augustinova, 2015; Experiment 2). Differences in color-naming RTs are thought to result from the selective presence of different types of conflict across these four types of items. The subtractive logic of this paradigm does not imply that before the actual color naming occurs, the contribution of these different conflicts to overall (i.e., standard) Stroop interference is strictly sequential (i.e., a more complex interaction between different types of conflicts might occur). Therefore, the contribution of these different conflicts might not be necessarily accumulative.

Additionally, the positive difference in mean response latencies between colorassociated and color-neutral trials (e.g., $S K Y_{\text {green }}-D O G_{\text {green, }}$, see Figure 1) was expected to

\footnotetext{
${ }^{4}$ Results of Mahé, Bonnefond, Gavens, Dufour, \& Doignon-Camus (2012) further depicted in the Discussion section are consistent with the idea - also predicted by bi-modal interactive activation model with (amodal) semantics - that task conflict is also present in color-neutral letter-strings (e.g., $X X X_{\text {green }}$, but see e.g., Kalanthroff et al., 2013, 2014; Goldfarb \& Henik, 2007 for a different view).
} 
isolate the specific contribution of semantic conflict to overall Stroop interference (i.e., a contribution that is independent of that of the response conflict). Finally, the positive difference in mean response latencies between standard color-incongruent and colorassociated trials (e.g., $B L U E_{\text {green }}-S K Y_{\text {green }}$, see Figure 1) was expected to capture the specific contribution of response conflict to overall Stroop interference. These different predictions were tested with the extended version of the semantic Stroop paradigm administered with both manual (Experiment 1) and vocal (Experiment 2) responses.

The second objective of this study was to empirically assess whether and to what extent the respective contribution of the task, semantic and response conflicts can be reduced by the increased attentional focus on the relevant (i.e., color) dimension of Stroop stimuli across time that short RSIs are thought to promote (see e.g., De Jong et al., 1999; Jackson \& Balota, 2013, Parris, 2014). To this end, both Experiment 1 (using manual responses) and Experiment 2 (using vocal responses) contrasted a short RSI of $500 \mathrm{~ms}$ with a long RSI of $2000 \mathrm{~ms}$. The short RSI of $500 \mathrm{~ms}$ was adopted after a pretest in which none of the participants were able to perform the vocal task with a RSI shorter than $500 \mathrm{~ms}$.

By combining for the first time the extended semantic Stroop paradigm (see Figure 1) and a manipulation of the RSI (500 vs. $2000 \mathrm{~ms}$ ), this study therefore makes it possible to test directly whether short RSIs (as compared to long ones) reduce task (Parris, 2014), semantic (De Jong et al., 1999) or response conflict (Augustinova \& Ferrand, 2014b). This unique design thus also enables us to further assess the nature of processes (automatic vs. controllable) involved in these conflicts.

\section{Experiment 1}

\subsection{Method}

\subsubsection{Participants}


Seventy-nine psychology undergraduates (69 females and 10 males, all native Frenchspeakers reporting normal or corrected-to-normal vision, $\mathrm{M}_{\mathrm{age}}=19.72$ years) at Blaise Pascal University, Clermont-Ferrand, France took part in this experiment (40 participants in the short RSI condition and 39 in the long RSI condition) in exchange for a course credit.

\subsubsection{Design and Stimuli}

Since the participants were randomly assigned to one of the two RSI conditions, the data was collected using a 4 (Stimulus-type: standard color-incongruent words vs. associated color-incongruent words vs. color-neutral words vs. color-neutral letter strings) $\times 2$ (RSI: short vs. long) design, with RSI as a between-participants factor. There were 60 trials for each Stimulus-type factor condition, whose presentation order was randomly determined for each participant within a single block of 240 experimental trials.

The stimuli (presented in lowercase 18-point Courier font on a black background) consisted of four color words: rouge [red], jaune [yellow], bleu [blue], and vert [green]; four color-associated words: tomate [tomato], maïs [corn], ciel [sky], and salade [salad]; four color-neutral words: balcon [balcony], robe [dress], pont [bridge] and chien [dog]; and strings of Xs of the same length as the color-incongruent trials. In each condition, all the stimuli were similar in length $(4.5,5,4.75$ and 4.75 letters on average for the color-incongruent words, the color-associated words, the color-neutral words and the strings of Xs respectively) and frequency $(74,82$ and 84 occurrences per million for the color-incongruent words, the colorassociated words and the color-neutral words, respectively) according to Lexique (New, Pallier, Brysbaert, \& Ferrand, 2004) ${ }^{5}$. Color-incongruent and color-associated items always appeared in colors that were incongruent with the meaning of their word-dimension.

\subsubsection{Apparatus and Procedure}

EPrime 2.1 (Psychology Software Tools, Pittsburgh) running on a PC (Dell Precision)

\footnotetext{
${ }^{5}$ Note, however, that, by definition, strings of Xs have a zero frequency value in Lexique.
} 
was used for stimulus presentation and data collection. The participants were seated approximately $50 \mathrm{~cm}$ from a 17 -inch Dell color monitor. Their task was to identify the color of the letter-strings presented on the screen as quickly and accurately as possible while ignoring their meanings. To this end, the participants were instructed to fixate the white cross ("+”"), which, depending on RSI condition, appeared in the center of the (black) screen for either 500 ms or 2000 ms (see e.g., Notebaert \& Soetens, 2003; Parris, Dienes, \& Hodgson, 2012 , for a similar procedure). The cross was then replaced by a letter-string that continued to be displayed until the participant responded (or until $3500 \mathrm{~ms}$ had elapsed). Since the participant's response started the RSI, a new fixation point was displayed at the beginning of the response. The participants responded using a keyboard placed on a table between the participant and the monitor. The keys were labeled with colored stickers, with key "1" representing red, key “2” representing green, key “3” representing "blue” and key “4” representing "yellow".

Before the beginning of the experimental block, the participants practiced learning which key on the keyboard represented each color (key-matching practice trials). In these 128 practice trials (MacLeod, 2005), strings of asterisks (presented in the four colors) were used (instead of the experimental stimuli, see above) and the RSI duration corresponded to each participant's condition (i.e., the white fixation cross that preceded the strings of asterisks remained on the black screen for either 500 or $2000 \mathrm{~ms}$ ).

\subsection{Results and Discussion}

Latencies greater than $3 S D$ s above or below each participant's mean latency for each condition (i.e., less than $2 \%$ of the total data) were excluded from the analyses. Mean correct manual-latencies were analyzed with a 4 (Stimulus-type: standard color-incongruent words vs. associated color-incongruent words vs. color-neutral words vs. color-neutral letter strings) 
$\times 2$ (RSI: short vs. long) ANOVA. This analysis revealed main effects of Stimulus-type $\left[F(3,231)=78.14 ; p<.001, \eta_{p}{ }^{2}=.50\right]$ and of RSI $\left[F(1,77)=18.20 ; p<.001, \eta_{p}{ }^{2}=.19\right]$ as well as a Stimulus-type $\times$ RSI interaction $\left[F(3,231)=5.31 ; p=.001, \eta_{p}{ }^{2}=.06\right]^{6}$.

In order to assess the extent to which the distinct contribution of the task, semantic and response conflicts can reliably be captured within the semantic Stroop paradigm administered with manual responses, the latter interaction was decomposed by testing the simple main effect of Stimulus-type at each level of RSI. This decomposition revealed that the simple main effect of Stimulus-type was significant in both the short- $\left[F(3,75)=16.85 ; p<.001, \eta_{p}{ }^{2}=.40\right]$ and long-RSI conditions $\left[F(3,75)=37.19 ; p<.001, \eta_{p}{ }^{2}=.60\right]$.

Further contrast analyses revealed that in both RSI conditions, latencies for standardincongruent words were significantly longer than those observed for associated colorincongruent words (both $p_{s}<.01$, see Table 1 for all related statistics) and that latencies for these associated color-incongruent words were significantly longer than those observed for color-neutral words (both $p_{s}<.001$, see Table 1 for all related statistics). These significant differences indicate that the distinct contributions of the response and semantic conflict occurred with both the short and long RSIs.

\footnotetext{
${ }^{6}$ The same analysis on error rates did not reveal any of these effects; see Table 1 for descriptive statistics on error rates.
} 


\section{Table 1}

Mean correct response times (in milliseconds), standard errors (in parentheses), and percentages of errors observed in Experiments 1 and 2 as a function of Stimulus-type and RSI.

\begin{tabular}{|c|c|c|c|c|c|c|}
\hline \multirow[b]{2}{*}{ Stimulus-type } & \multicolumn{3}{|c|}{$\begin{array}{l}\text { Experiment } 1 \\
\text { (Manual Task) }\end{array}$} & \multicolumn{3}{|c|}{$\begin{array}{l}\text { Experiment } 2 \\
\text { (Vocal Task) }\end{array}$} \\
\hline & $\begin{array}{c}\text { Long- } \\
\text { RSI } \\
(2000 \mathrm{~ms})\end{array}$ & & $\begin{array}{c}\text { Short- } \\
\text { RSI } \\
(500 \mathrm{~ms})\end{array}$ & $\begin{array}{c}\text { Long- } \\
\text { RSI } \\
(2000 \mathrm{~ms})\end{array}$ & & $\begin{array}{c}\text { Short- } \\
\text { RSI } \\
(500 \mathrm{~ms})\end{array}$ \\
\hline $\begin{array}{l}\text { Standard color-incongruent words } \\
\qquad B L U E_{\text {green }}\end{array}$ & $\begin{array}{l}813 \\
(19) \\
1.71\end{array}$ & & $\begin{array}{l}696 \\
(18) \\
2.50\end{array}$ & $\begin{array}{l}809 \\
(22) \\
4.56\end{array}$ & & $\begin{array}{l}799 \\
(24) \\
6.15\end{array}$ \\
\hline $\begin{array}{l}\text { Associated color-incongruent words } \\
\qquad S K Y_{\text {green }}\end{array}$ & $\begin{array}{l}769 \\
(17) \\
1.28\end{array}$ & & $\begin{array}{l}677 \\
(16) \\
1.71\end{array}$ & $\begin{array}{l}730 \\
(17) \\
1.13\end{array}$ & & $\begin{array}{l}751 \\
(19) \\
1.49\end{array}$ \\
\hline $\begin{array}{l}\text { Color-neutral words } \\
\qquad D O G_{\text {green }}\end{array}$ & $\begin{array}{l}745 \\
(16) \\
1.16\end{array}$ & & $\begin{array}{l}658 \\
(15) \\
1.91\end{array}$ & $\begin{array}{l}701 \\
(15) \\
0.78\end{array}$ & & $\begin{array}{l}724 \\
(16) \\
1.32\end{array}$ \\
\hline $\begin{array}{l}\text { Color-neutral signs } \\
\qquad X X X_{\text {green }}\end{array}$ & $\begin{array}{l}738 \\
(15) \\
1.34\end{array}$ & & $\begin{array}{l}650 \\
(14) \\
2.12\end{array}$ & $\begin{array}{l}653 \\
(15) \\
0.49\end{array}$ & & $\begin{array}{l}685 \\
(16) \\
0.57\end{array}$ \\
\hline \multicolumn{7}{|l|}{ Contribution of } \\
\hline \multirow{2}{*}{$\begin{array}{l}\text { Task conflict } \\
\qquad\left(D O G_{\text {green }}-X X X_{\text {green }}\right)\end{array}$} & +7 & $\approx$ & +8 & +48 & $=$ & +39 \\
\hline & $\begin{array}{c}F(1,77)= \\
2.50 \\
p=.12 \\
\eta_{p}{ }^{2}=.03\end{array}$ & & $\begin{array}{c}F(1,77)= \\
3.22 \\
p=.08 \\
\eta_{p}^{2}=.04\end{array}$ & $\begin{array}{c}F(1,61)= \\
57.31 \\
p<.001 \\
\eta_{p}^{2}=.48\end{array}$ & & $\begin{array}{c}F(1,61)= \\
32.02 \\
p<.001 \\
\eta_{p}{ }^{2}=.34\end{array}$ \\
\hline \multirow{2}{*}{$\begin{array}{l}\text { Semantic conflict } \\
\quad\left(S K Y_{\text {green }}-D O G_{\text {green }}\right)\end{array}$} & +24 & $=$ & +19 & +29 & $=$ & +27 \\
\hline & $\begin{array}{c}F(1,77)= \\
48.10 \\
p<.001 \\
\eta_{p}{ }^{2}=.39\end{array}$ & & $\begin{array}{c}F(1,77)= \\
31.56 \\
p<.001 \\
\eta_{p}^{2}=.29\end{array}$ & $\begin{array}{c}F(1,61)= \\
33.78 \\
p<.001 \\
\eta_{p}^{2}=.36\end{array}$ & & $\begin{array}{c}F(1,61)= \\
24.55 \\
p<.001 \\
\eta_{p}{ }^{2}=.29\end{array}$ \\
\hline \multirow[t]{2}{*}{$\begin{array}{l}\text { Response conflict } \\
\qquad\left(B L U E_{\text {green }}-S K Y_{\text {green }}\right)\end{array}$} & +44 & $>$ & +19 & +78 & $>$ & +48 \\
\hline & $\begin{array}{c}F(1,77)= \\
41.85 \\
p<.001 \\
\eta_{p}{ }^{2}=.35\end{array}$ & & $\begin{array}{c}F(1,77)= \\
7.80 \\
p<.01 \\
\eta_{p}{ }^{2}=.09\end{array}$ & $\begin{array}{c}F(1,61)= \\
67.45 \\
p<.001 \\
\eta_{p}{ }^{2}=.53\end{array}$ & & $\begin{array}{c}F(1,61)= \\
21.99 \\
p<.001 \\
\eta_{p}{ }^{2}=.27\end{array}$ \\
\hline \multirow{2}{*}{$\begin{array}{l}\text { Overall Stroop interference } \\
\text { (Sum of task, semantic, and response conflicts) }\end{array}$} & +75 & $>$ & +46 & +155 & $>$ & +114 \\
\hline & $\begin{array}{c}F(1,77)= \\
75.80 \\
p<.001 \\
\eta_{p}{ }^{2}=.50\end{array}$ & & $\begin{array}{c}F(1,77)= \\
29.26 \\
p<.001 \\
\eta_{p}{ }^{2}=.28\end{array}$ & $\begin{array}{c}F(1,61)= \\
187.64 \\
p<.001 \\
\eta_{p}{ }^{2}=.76\end{array}$ & & $\begin{array}{c}F(1,61)= \\
86.30 \\
p<.001 \\
\eta_{p}{ }^{2}=.59\end{array}$ \\
\hline
\end{tabular}


However, in the long-RSI condition, latencies for color-neutral words were statistically equivalent to those observed for color-neutral letter strings $(p=0.12, n s)$, while in the short-RSI condition, this contrast was only marginally significant ( $p=0.08, n s$; see Table 1). These latter results suggest that at both fast and normal rate (i.e., short and long RSI), some specific contribution of the task conflict occurs ( 7 and $8 \mathrm{~ms}$ respectively, see Table 1) but fails to contribute significantly to the overall Stroop interference observed in the semantic Stroop paradigm administered with manual responses. It was therefore impossible to assess whether RSI actually influences task conflict.

To further assess empirically the issue of whether and to what extent these significant contributions of semantic and response conflicts can be reduced by short RSIs, the amplitudes of their respective contributions ${ }^{7}$ were subsequently analyzed in a 2 (Conflict-type: semantic vs. response) $\times 2$ (RSI: short vs. long) ANOVA. This analysis revealed that the contribution of the semantic conflict to the overall interference remained unaffected by the variations in RSI: the magnitude of this conflict not only remained significant (24 vs. $19 \mathrm{~ms}$, see Table 1) but was also statistically equivalent in the short- and long-RSI conditions respectively; $[F(1,77)=$ $\left.\left.0.98 ; p=.33, n s, \eta_{p}{ }^{2}=.01\right]\right)$. In sharp contrast, short RSIs reduced the contribution of response conflict to overall Stroop interference. Indeed, the magnitude of this conflict fell from $44 \mathrm{~ms}$ in the long-RSI condition to $19 \mathrm{~ms}$ in the short-RSI condition $[F(1,77)=6.98 ; p=$ $\left..01, \eta_{p}^{2}=.08\right]$

Taken together, these results replicate past studies showing that a short RSI (i.e., RSI of $500 \mathrm{~ms}$ compared to $2000 \mathrm{~ms}$ ) decreases the magnitude of overall Stroop interference (De Jong et al., 1999; Jackson \& Balota, 2013; Parris, 2014). However, contrary to the initial assumption of De Jong and colleagues, this decrease in magnitude is likely to be due to the reduced contribution of response conflict but not that of semantic conflict (see e.g.,

\footnotetext{
${ }^{7}$ It should be noted that these contrasts are not statistically orthogonal (see e.g., Levin, 2015; Levin \& Tzelgov, 2016 for discussions) but these comparisons were performed to address the associated theoretical issue directly.
} 
Augustinova \& Ferrand, 2014b). Given that in the present experiment we failed to capture the distinct contribution of task conflict (i.e., a contribution that is independent of the semantic and response conflicts) to the overall Stroop interference observed in the semantic paradigm administered with manual responses, the extent to which a short RSI specifically reduces this type of conflict (Parris, 2014) remains an open issue.

In the following experiment, we therefore examined the extent to which a short (as opposed to a long) RSI condition reduces the Stroop interference observed with vocal responses (i.e., say “green" instead of press green button for $\left.B L U E_{\text {green }}\right)$. Indeed, the amplitude of the Stroop interference observed with vocal responses is considerably larger than that observed with manual responses (e.g., Augustinova \& Ferrand, 2014a; Brown, Joneleit, Robinson, \& Brown, 2002; Sharma \& McKenna, 1998). Consequently, the contribution of the different types of conflict (including that of task conflict) should increase correspondingly, thus making it easier to detect the specific contribution of task conflict.

\section{Experiment 2}

\subsection{Method}

Seventy-eight additional psychology undergraduates from the same pool of participants (see above) were assigned to either the short or the long RSI condition. The data for 15 participants were excluded from the analyses (10 in the short RSI condition ${ }^{8}$ and 5 in the long RSI condition'), leaving a total of 63 participants (61 females and 2 males, all native French-speakers reporting normal or corrected-to-normal vision; $\mathrm{M}_{\mathrm{age}}=19.27$ years). They were familiarized with the task during a set of twelve practice trials and their vocal responses

\footnotetext{
8 Three participants made more than $33 \%$ errors; irrelevant mouth/tongue movements triggered the voice-key prematurely for 2 participants and 5 participants did not respond to more than $33 \%$ of trials since the vocal task was difficult to accomplish with an RSI of $500 \mathrm{~ms}$.

${ }^{9}$ Two participants made more than $33 \%$ errors; the microphone did not detect responses for 2 participants and EPrime failed to record the responses for 1 participant.
} 
were recorded via a Koss 70dB microphone headset and stored on a Sony recorder model ICD-PX333. All other methodological aspects were identical to those of Experiment 1.

\subsection{Results and Discussion}

Latencies greater than $3 S D$ s above or below each participant's mean latency for each condition (i.e., less than $3 \%$ of the total data) were excluded from the analyses. Mean correct naming-latencies were analyzed with a 4 (Stimulus-type: standard color-incongruent words vs. associated color-incongruent words vs. color-neutral words vs. color-neutral letter strings) $\times 2$ (RSI: short vs. long) ANOVA. This analysis revealed a main effect of Stimulus-type $[F(3$, $\left.183)=155.95 ; p<.001, \eta_{p}{ }^{2}=.72\right]$ which also interacted with $\operatorname{RSI}[F(3,183)=3.92 ; p=.01$, $\left.\eta_{p}{ }^{2}=.06\right]^{10}$. The main effect of RSI remained non-significant $\left[F(1,61)=0.47 ; p=.50, \eta_{p}{ }^{2}=\right.$ $.01]$, indicating that short RSIs failed to reduce naming latencies overall (see Table 1, see also e.g., Jackson \& Balota, 2013 for a similar result).

As in Experiment 1, the RSI $\times$ Stimulus-type interaction was decomposed in order to assess the extent to which the distinct contribution of the task, semantic and response conflicts can reliably be captured within the semantic Stroop paradigm administered with vocal responses. This decomposition revealed that the simple main effect of Stimulus-type was significant in both the short- $\left[F(3,59)=31.10 ; p<.001, \eta_{p}{ }^{2}=.61\right]$ and the long-RSI conditions $\left[F(3,59)=62.83 ; p<.001, \eta_{p}{ }^{2}=.76\right]$. Further contrast analyses revealed that in both RSI conditions, latencies for all four types of items were significantly different from each other (all $p_{s}<.001$, see Table 1 for all related statistics). These differences show that at both fast and normal task rate (induced by the short and long RSI, respectively), the specific contribution of all types of conflict (task, semantic and response conflict) to the overall Stroop interference observed in the semantic Stroop paradigm administered with vocal responses is

\footnotetext{
${ }^{10}$ The same analysis on error rates revealed only a main effect of Stimulus-type $\left[F(3,183)=66.49 ; p<.001, \eta_{p}{ }^{2}\right.$ $=.52]$ that yielded a fairly common linear trend showing that color-incongruent items were the most and colorneutral signs the least error-prone $\left(\left[F(1,61)=91.74 ; p<.001, \eta_{p}{ }^{2}=.60\right]\right.$; see Table 1 for descriptive statistics $)$.
} 
indeed significant.

The remaining issues of whether and to what extent the aforementioned significant contributions of the task, semantic and response conflicts can be reduced by short RSIs were tested in a 3 (Conflict-type: task vs. semantic vs. response) $\times 2$ (RSI: short vs. long) ANOVA.

This revealed that the specific contributions of task and semantic conflicts to overall Stroop interference remained unaffected by variations in RSI. The magnitudes of these contributions remained significant and statistically equivalent in both the long and the short RSI conditions for task conflict [ 48 vs. $\left.39 \mathrm{~ms}, F(1,61)=0.96 ; p=.33, n s, \eta_{p}{ }^{2}=.015\right]$ and for semantic conflict [ 29 vs. $\left.\left.27 \mathrm{~ms}, F(1,61)=0.09 ; p=.76, n s, \eta_{p}{ }^{2}=.002\right]\right)$. However, as in Experiment 1, short RSIs significantly reduced the specific contribution of response conflict to overall Stroop interference, with the result that its magnitude fell from $78 \mathrm{~ms}$ in the longRSI condition to $48 \mathrm{~ms}$ in the short-RSI condition $\left[F(1,61)=4.53 ; p=.04, \eta_{p}{ }^{2}=.07\right]$. Thus, this experiment replicates and extends the pattern of results reported in Experiment 1 to the vocal-response modality.

\section{General Discussion}

As mentioned above, single-stage response competition accounts which hold that Stroop interference results solely from a response conflict have historically been favored in the Stroop literature over both early selection (see e.g., MacLeod, 1991) and multi-stage (see e.g., Risko et al., 2006) accounts. Given their historically rooted importance, they still largely dominate both empirical research and clinical practice.

To give just one example, the Stroop task is typically considered as "a prototypical inhibition task (...) in which one needs to inhibit or override the tendency to produce a more dominant or automatic response (i.e., name the color word)" and the magnitude of Stroop interference as reflecting “one's ability to deliberately inhibit dominant, automatic, or 
prepotent responses when necessary" (Miyake, Friedman, Emerson, Witzki, \& Howerter, 2000, p.57).

However, over the last twenty years, a large number of different arguments and demonstrations have indicated that this view of Stroop interference is far from being complete (see e.g., Augustinova \& Ferrand, 2014b; De Houwer, 2003a; Goldfarb \& Henik, 2007; Kalanthroff et al., 2013a, b; Levin \& Tzelgov, 2014, 2016; MacLeod \& MacDonald, 2000; Manwell et al., 2004; Monsell et al., 2001; Neely \& Kahan, 2001; Parris, 2014; Schmidt \& Cheesman, 2005; Zhang \& Kornblum, 1998).

Despite this, many researchers and practitioners who are interested in Stroop interference itself and/or in its measurement still seem to be unaware that it goes far beyond a mere response competition and that it should thus be implemented or at least interpreted accordingly. We consider that there are three likely reasons for the current state of art.

The first lies in the flagrant lack of any consensus between the different multi-stage accounts concerning the types of conflict, and thus the components, that Stroop interference actually involves.

The second reason is linked to the lack of knowledge about the extent to which these components are accessible to cognitive control - an issue of considerable interest to our scientific community (in its broadest sense). Indeed, the possibility of cognitive control is generally simply inferred from the reduction of the overall Stroop interference, even though its existence (or the lack thereof) should logically be demonstrated directly (i.e., at the level of the actual components of Stroop interference that mobilize specific types of conflicts).

The third, and perhaps final reason, for this state of art resides in the current lack of an experimental protocol that is not only able to capture the specific contribution of the different components of Stroop interference and of their modulation, but that is also simple enough to be administered in both lab and field (i.e., clinical) settings (see e.g. Augustinova et al., 2016 
for a discussion of this issue). Consequently, and in line with the scope of this volume, this paper has attempted to tackle these different issues together.

With respect to the first issue, the present paper departed from an integrative perspective by considering that - in addition to the response conflict assumed by two different types of multi-stage accounts (i.e., TC-RC and SC-RC accounts) -, task and semantic conflict (i.e., conflicts variously assumed by these accounts) also contribute to overall Stroop interference. In line with this idea, the empirical work presented in this paper consequently attempted to capture the specific contribution of these three types of conflict by means of a relatively simple experimental protocol. More specifically, it attempted to extend the existing semantic Stroop paradigm - which in its original form distinguishes between the respective contributions of semantic and response conflict - in such a way that it can take account of and capture the specific contribution of task conflict.

To this end, in the two experiments reported above, color-neutral letter-strings (e.g., $\left.X X X X_{\text {green }}\right)$ were used in addition to the standard color-incongruent (e.g., $\left.B L U E_{\text {green }}\right)$, associated color-incongruent (e.g., $S K Y_{\text {green }}$ ) and color-neutral (e.g., $\left.D O G_{\text {green }}\right)$ words that are commonly used in this paradigm. Thanks to this operationalization, the specific contributions of task (e.g., $\left.D O G_{\text {green }}-X X X X_{\text {green }}\right)$, semantic (e.g., $\left.S K Y_{\text {green }}-D O G_{\text {green }}\right)$ and response conflict (e.g., $B L U E_{\text {green }}-S K Y_{\text {green }}$, see Figure and Table 1) to overall Stroop interference were captured in both experiments. Despite this, it was not possible to reliably capture the specific contribution of task conflict (as opposed to semantic and response conflicts) when the semantic Stroop paradigm was administered with manual (Experiment 1) as opposed to vocal responses (Experiment 2).

Additional empirical evidence is needed to clarify whether this constitutes a stable result or whether it is due to the rather modest sample size (i.e., about 40 participants in each RSI condition). Indeed, given that with manual responses, the specific behavioral 
manifestation of task conflict (but also of semantic conflict) is relatively small (see e.g., Augustinova, 2015; Sharma \& McKenna, 1998), a larger sample size than is usually found in Stroop research might be of value in future empirical research (see e.g., Risko et al., 2006 for an example and Augustinova \& Ferrand, 2014b for a discussion).

It is also plausible that the significant contribution of this early component can still be found in electrophysiological measures such as ERPs (see e.g., Heil, Rolke, \& Pecchinenda, 2004). This assumption is supported by the fact that in skilled readers (as opposed to individuals with developmental dyslexia), larger left occipito-temporal negativities - also referred to N170 tuning for print - for meaningless letter-stings (e.g., fbnrc) than for symbol strings (e.g., §ð†Ø£) occur as early as 135-255 ms after stimulus onset (Mahé et al., 2012). Again, future research needs to address this possibility directly.

The fact that the behavioral manifestation of all three types of conflict can be clearly seen in the Stroop interference observed within the semantic Stroop paradigm administered with vocal responses (Experiment 2) suggests that this paradigm constitutes already a viable avenue of research. At a more general level, it also emphasizes the viability of different multistage accounts and, more specifically, the fact that the two types of multi-stage accounts can easily be integrated in one overarching framework (see e.g., Levin, 2015; Levin \& Tzelgov, 2016 for the initial impetus towards this direction).

With regard to the second issue outlined above (i.e., the lack of knowledge about the actual accessibility of the different components of Stroop interference to cognitive control), the present paper examined whether and to what degree the specific contributions of these components can be controlled through a consistent attentional focus on the relevant (i.e., color) dimension of Stroop words across time (De Jong, Berendsen, \& Cools, 1999; De Jong et al., 1999; Jackson \& Balota, 2013; Parris, 2014). To this end, both experiments also contrasted a short RSI of $500 \mathrm{~ms}$ (i.e., a condition that is likely to produce an increased 
attentional selectivity) with a long RSI of $2000 \mathrm{~ms}$.

In both experiments, and in line with past studies, the magnitude of Stroop interference was significantly reduced by short RSIs. However, this overall reduction was specifically due to the significantly smaller contribution of response conflict and not to that of semantic and task conflict as has been assumed in past research (De Jong et al., 1999; Parris, 2014). Indeed, perhaps the most significant empirical contribution of this paper comes from that fact that - in contrast to past research in this area -, the latter finding was revealed by a study specifically involving a careful distinction between all the different types of conflict that contribute to Stroop interference.

These findings are thus consistent with previous results reported by Augustinova and colleagues showing that various interventions known to reduce overall Stroop interference (e.g., Besner et al., 1997; Goldfarb et al., 2011) specifically reduce the magnitude of the response conflict (as opposed to the semantic conflict, see e.g. Augustinova \& Ferrand, $2014 \mathrm{~b}$, for a review). Since the semantic conflict (unlike the response conflict) constitutes a suitable behavioral proxy for assessing the influence of word meaning in a Stroop task (e.g. Augustinova \& Ferrand, 2014b; Neely \& Kahan, 2001), the current results imply that, contrary to De Jong and colleagues' initial reasoning, variations in RSIs have absolutely no influence on the inhibition of word meaning.

It should be noted that the present results do not rule out the idea, suggested by De Jong and colleagues, that the fast task rate enables individuals to mobilize their inhibitory capabilities more effectively. However, the results reported above suggest that this is beneficial only for processes that occur after the processing of word meaning, most probably because word reading (and the semantic conflict that it entails) is automatic and thus insensitive to cognitive control (but see e.g., Besner et al., 2016 for a different view). The specific contribution of task conflict (i.e., a contribution that is independent of the 
semantic and response conflicts) to Stroop interference observed in the semantic paradigm administered with manual responses (Experiment 1) was insufficient to allow us to directly examine the claim put forward by Parris (2014). Parris suggested that a consistent attentional focus on the relevant (i.e., color) dimension of Stroop words across time induced by short RSIs significantly reduces task conflict.

However, contrary to this latter claim, and in line with Levin and Tzelgov's (2014, see also e.g., Levin, 2015) idea that task conflict might be insensitive to cognitive control, the magnitude of the task conflict observed with vocal responses (Experiment 2) remained significant and statistically equivalent in both RSI-conditions. Therefore, in just the same way as semantic conflict, task conflict appears to be generally insensitive to cognitive control - in line with its conceptualization within the bi-modal interactive activation model (McClelland \& Rumelhart, 1981; McClelland, 1987; Grainger \& Ferrand, 1994, 1996; Grainger \& Holcomb, 2009) discussed above.

The arguments suggested above suggest that variations in RSI should only affect the processing of standard color-incongruent words, which (unlike the other stimuli) involve a significant amount of response conflict (see Parris, 2014, for such a pattern). However, this prediction was difficult to test in the current study because, unlike in Parris, 2014 (but in exactly the same way as in De Jong et al., 1999), the RSIs were manipulated at betweenparticipants level and this manipulation also affected the speed of processing. Thus, further empirical work will be required in order to clarify the extent to which the difference between Parris's results (2014) and those reported above are due to differences in experimental designs.

Meanwhile, these divergent findings point to the fact that the effects of RSIs in the Stroop task are far from being fully understood. It should be remembered that previous studies have agreed in assuming that a fast task pace (i.e., short RSIs) promotes attentional 
focus on the relevant (i.e., color) dimension of Stroop stimuli across time (see e.g., De Jong et al., 1999; Jackson \& Balota, 2013; Parris, 2014). It remains plausible that this influence is exerted early in processing (i.e., at the time of the input). Nevertheless, and in line with the automatic nature of the process involved in both task and semantic conflict, the benefit of this increased attentional selectivity is seen only at a late stage - at the level of controllable response processing. Again, future research needs to further explore this still-unresolved issue directly - preferably by supplementing standard chronometric measures with others that are sensitive to the time course of Stroop interference (see e.g. Augustinova et al., 2015; Killikelly \& Szücs, 2013; Szücs \& Soltész, 2010).

Finally, with respect to the last issue outlined above, the fact that the specific contribution of all three types of conflict, as well as the modulation of these distinct contributions, can be clearly seen within the semantic Stroop paradigm administered with vocal responses (Experiment 2) might make it possible to construct an evaluation tool that is simple enough to be administered in both lab and field (i.e., clinical) settings.

One advantage of this paradigm is that it is not restricted to manual responses as is the case with the so-called 2-to-1 paradigm (De Houwer, 2003; see also e.g., Hasshim \& Parris, 2014, 2015; Van Veen \& Carter, 2005), for instance, which also arose from SC-RC accounts. This is important because the semantic Stroop paradigm can be administered not only using an item-by-item (i.e., computerized) presentation but also, potentially, in a card version that is still in widespread use in clinical practice (see e.g., Bugg, DeLosh, Davalos, \& Davis, 2007 for an example and Augustinova \& Ferrand, 2014b; Augustinova et al., 2016 for discussions of this issue). Since the semantic Stroop task is rooted in multi-stage accounts, it might be more efficient in capturing more subtle effects such as that exerted by healthy aging on Stroop interference (e.g., Bugg et al., 2007) and its known moderators (e.g., Jackson \& Balota, 2013; see also Li \& Bosman, 1996 for an initial impetus towards this research direction). 
Indeed, perhaps the most important lesson to be learned from the present paper is that the standard implementation of the Stroop paradigm, which contrasts mean coloridentification times for color-incongruent items (e.g., $\left.B L U E_{\text {green }}\right)$ with some kind of colorneutral (e.g., $D O G_{\text {green }} / X X X_{\text {green }}$ ) or color-congruent (e.g., $B L U E_{\text {blue }}$ ) baseline, should be abandoned in favor of a more fine-grained implementation such as the one used in the present paper. Indeed, contrary to the usual perspective adopted in Stroop research, the effects of known moderators such as RSIs might not occur (equally) for all components of overall Stroop interference. They might therefore remain undetected and/or be misinterpreted when observed within the standard implementation of the Stroop paradigm. 


\section{References}

Augustinova, M. (2015). The influence of response modality (manual vs. vocal) in the Stroop task. Paper presented at the $19^{\text {th }}$ Conference of the European Society for Cognitive Psychology, Paphos, Cyprus.

Augustinova, M., \& Ferrand, L. (2007). Influence de la présentation bicolore des mots sur l'effet Stroop [First-letter coloring and the Stroop effect]. L'Année Psychologique, 107, 163-179.

Augustinova, M., Flaudias, V., \& Ferrand, L. (2010). Single-letter coloring and spatial cuing do not eliminate or reduce a semantic contribution to the Stroop effect. Psychonomic Bulletin \& Review, 17, 827-833

Augustinova, M., \& Ferrand, L. (2012a). Suggestion does not de-automatize word reading: Evidence from the semantically based Stroop task. Psychonomic Bulletin \& Review, $19,521-527$.

Augustinova, M., \& Ferrand, L. (2012b). The influence of mere social presence on Stroop interference: New evidence from the semantically-based Stroop task. Journal of Experimental Social Psychology, 48, 1213-1216.

Augustinova, M., \& Ferrand, L. (2014a). Social priming of dyslexia and reduction of the Stroop effect: What component of the Stroop effect is actually reduced? Cognition, 130, 442-454.

Augustinova, M., \& Ferrand, L. (2014b). Automaticity of word reading: Evidence from the semantic Stroop paradigm. Current Directions in Psychological Science, 23, 343-348.

Augustinova, M., Silvert, L., Ferrand, L., Llorca, P. M., \& Flaudias, V. (2015). Behavioral and electrophysiological investigation of semantic and response conflict in the Stroop task. Psychonomic Bulletin \& Review, 22, 543-549.

Augustinova, M., Almeida, E., Clarys, D., Ferrand, L., Izaute, M., Jalenques, I., Juneau, C., 
Normand, A., \& Silvert, L. (2016). Que mesure l'interférence Stroop ? Arguments méthodologiques et théoriques en faveur d'un changement de pratiques dans sa mesure [What the Stroop interference actually measures? When and how? Methodological and theoretical arguments in favor of change in its measurement]. L'Année Psychologique/Topics in Cognitive Psychology, 116, 45-66.

Bench, C. J., Frith, C. D., Grasby, P. M., Friston, K. J., Paulesu, E., Frackowiak, R. S. J., et al. (1993). Investigations of the functional anatomy of attention using the Stroop test. Neuropsychologia, 31, 907-22.

Besner, D., Stolz, J. A., \& Boutilier, C. (1997). The Stroop effect and the myth of automaticity. Psychonomic Bulletin \& Review, 4, 221-225.

Besner, D., Risko, E. F., Stolz, J. A., White, D., Reynolds, M., O’Malley, S., \& Robidoux, S. (2016). Varieties of attention. Their roles in visual word identification. Current Directions in Psychological Science, 25, 162-168.

Braver, T. S. (2012). The variable nature of cognitive control: a dual mechanisms framework. Trends in Cognitive Sciences, 16, 106-113

Brown, T. L. (2011). The relationship between Stroop interference and facilitation effects: statistical artifacts, baselines, and a reassessment. Journal of Experimental Psychology: Human Perception and Performance, 37, 85-99.

Brown, T. L., Joneleit, K., Robinson, C. S., \& Brown, C. R. (2002). Automaticity in reading and the Stroop task: testing the limits of involuntary word processing. The American journal of psychology, 115, 515-543.

Bugg, J. M., DeLosh, E. L., Davalos, D. B., \& Davis, H. P. (2007). Age differences in Stroop interference: Contributions of general slowing and task-specific deficits. Aging, Neuropsychology, and Cognition, 14, 155 - 167.

Burt, J. S. (1999). Associative priming in color naming: Interference and facilitation. Memory 
\& Cognition, 27, 454-464.

Chen, Z., Lei, X., Ding, C., Li, H., \& Chen, A. (2013). The neural mechanisms of semantic and response conflicts: An fMRI study of practice-related effects in the Stroop task. NeuroImage, 66, 577-584.

Coderre, E. L.,Conklin, K., \& van Heuven, W. J. B.(2011). Electrophysiological measures of conflict detection and resolution in the Stroop task. Brain Research, 1413, 51-59.

Dalrymple-Alford, E. C., \& Budayr, B. (1966). Examination of some aspects of the Stroop color-word test. Perceptual and Motor skills, 23, 1211-1214.

Dalrymple-Alford, E. C. (1972). Associative facilitation and effect in the Stroop color-word task. Perception \& Psychophysics, 11, 274-276.

De Houwer, J. (2003). On the role of stimulus-response and stimulus-stimulus compatibility in the Stroop effect. Memory \& Cognition, 31, 353-359.

De Jong, R., Berendsen, E., \& Cools, R. (1999). Goal neglect and inhibitory limitations: dissociable causes of interference effects in conflict situations. Acta Psychologica, $101,379-394$.

Ferrand, L., \& Augustinova, M. (2014). Differential effects of viewing positions on standard versus semantic Stroop interference. Psychonomic Bulletin \& Review, 21, 425-430,

Fox, L. A., Shor, R. E., \& Steinman, R. J. (1971). Semantic gradients and interference in naming color, spatial direction, and numerosity. Journal of Experimental Psychology, $91,59-65$.

Goldfarb, L., \& Henik, A. (2006). New data analysis of the Stroop matching ask calls for a theory reevaluation. Psychological Science, 17, 96-100.

Goldfarb, L., \& Henik, A. (2007). Evidence for task conflict in the Stroop effect. Journal of Experimental Psychology: Human Perception and Performance, 33, 1170-1176.

Goldfarb, L., Aisenberg, D., \& Henik, A. (2011). Think the thought, walk the walk - Social 
priming reduces the Stroop effect. Cognition, 118, 193-200.

Grainger, J., \& Ferrand, L. (1994). Phonology and orthography in visual word recognition: Effects of masked homophone primes. Journal of Memory and Language, 33, 218 233.

Grainger, J., \& Ferrand, L. (1996). Masked orthographic and phonological priming in visual word recognition and naming: Cross-task comparisons. Journal of Memory and Language, 35, 623-647.

Grainger, J., \& Holcomb, P. J. (2009). Watching the word go by: On the time-course of component processes in visual word recognition. Language and Linguistics Compass, $3,128-156$.

Hasshim, N., \& Parris, B. A. (2014). Two-to-one color-response mapping and the presence of semantic conflict in the Stroop task. Frontiers in psychology, 5.

Hasshim, N., \& Parris, B. A. (2015). Assessing stimulus-stimulus (semantic) conflict in the Stroop task using saccadic two-to-one color response mapping and preresponse pupillary measures. Attention, Perception, \& Psychophysics, 77, 2601-2610.

Heil, M., Rolke, B., \& Pecchinenda, A. (2004). Automatic Semantic Activation Is No Myth Semantic Context Effects on the N400 in the Letter-Search Task in the Absence of Response Time Effects. Psychological Science, 15, 852-857.

Hock, H. S., \& Egeth, H. E. (1970). Verbal interference with encoding in a perceptual classification task. Journal of Experimental Psvchology, 83, 299-303.

Jackson, J. D., \& Balota, D. A. (2013). Age-related changes in attentional selection: Quality of task set or degradation of task set across time? Psychology and Aging, 28, 744-753.

Kalanthroff, E., Goldfarb, L., \& Henik, A. (2013a). Evidence for interaction between the stopsignal and the Stroop task conflict. Journal of Experimental Psychology: Human Perception and Performance, 39, 579-592. 
Kalanthroff, E., Goldfarb, L., Usher, M., \& Henik, A. (2013b). Stop interfering: Stroop task conflict independence from informational conflict and interference. Quarterly Journal of Experimental Psychology, 66, 1356-1367.

Kalanthroff, E, \& Henik, A. (2013b). Individual but not fragile: Individual differences in task control predict Stroop facilitation. Consciousness and Cognition, 22, 413-419.

Killikelly, C., \& Szücs, D. (2013). Asymmetry in stimulus and response conflict processing across the adult lifespan: ERP and EMG evidence. Cortex, 49, 2888-2903.

Klein, G. S. (1964). Semantic power measured through the effect of words with color-naming. American Journal of Psychology, 77, 576-588.

Levin, Y. (2015). Stroop conflict components and their control. Doctoral dissertation, Ben Gourion University of the Negev, Beer-Sheva, Israel.

Levin, Y., \& Tzelgov, J. (2014). Conflict components of the Stroop effect and their "control". Frontiers in Psychology, 5:463. doi: 10.3389/fpsyg.2014.00463

Levin, Y, \& Tzelgov, J. (2016). What Klein's "semantic gradient" does and does not really show: Decomposing Stroop interference into task and informational conflict components. Frontiers in Psychology, 7:249. doi: 10.3389/fpsyg.2016.00249

Li, K. Z. H., \& Bosman, E. A. (1996). Age differences in Stroop-like interference as a function of semantic relatedness. Aging, Neurospychology, and Cognition, 3, 272-294.

Luo, C. R. (1999). Semantic competition as the basis of the Stroop interference: Evidence from color-word matching tasks. Psychological Science, 10, 35-40.

Logan, G. D., \& Zbrodoff, N. J. (1998). Stroop-type interference: Congruity effects in color naming with typewritten responses. Journal of Experimental Psychology: Human Perception and Performance, 24, 978.

MacLeod, C. M. (1991). Half a century of research on the Stroop effect: An integrative review. Psychological Bulletin, 109, 163-203 
MacLeod, C. M. (1992). The Stroop task: The" gold standard" of attentional measures. Journal of Experimental Psychology: General, 121, 12-14.

MacLeod, C. M. (2005). The Stroop task in cognitive research. In A. Wenzel \& D. C. Rubin (Eds.), Cognitive methods and their application to clinical research (pp. 17-40). Washington, DC: American Psychological Association.

MacLeod, C. M., \& MacDonald, P. A. (2000). Interdimensional interference in the Stroop effect: Uncovering the cognitive and neural anatomy of attention. Trends in Cognitive Sciences, 4, 383-391.

Mahé, G., Bonnefond, A., Gavens, N., Dufour, A., \& Doignon-Camus, N. (2012). Impaired visual expertise for print in French adults with dyslexia as shown by N170 tuning. Neuropsychologia, 50, 3200-3206.

Manwell, L. A., Roberts, M. A., \& Besner, D. (2004). Single letter coloring and spatial cueing eliminates a semantic contribution to the Stroop effect. Psychonomic Bulletin \& Review, $11,458-462$.

McClelland, J. L. (1987). The case of interactionism in language processing. In M. Coltheart (Ed.), Attention and Performance XII: The psychology of reading (pp. 3-36). London: Erlbaum.

McClelland, J. L., \& Rumelhart, D. E. (1981). An interactive activation model of context effects in letter perception: Part 1. An account of basic finding. Psychological Review, $88,375-407$.

Miyake, A., Friedman, N. P., Emerson, M. J., Witzki, A. H., Howerter, A., \& Wager, T. D. (2000). The unity and diversity of executive functions and their contributions to complex "frontal lobe" tasks: A latent variable analysis. Cognitive Psychology, 41, 49100.

Monsell, S., Taylor, T. J., \& Murphy, K. (2001). Naming the color of a word: Is it responses or 
task sets that compete? Memory \& Cognition, 29, 137-151.

Neely, J. H., \& Kahan, T. (2001). Is semantic activation automatic? A critical re-evaluation. In H. L. Roediger III, J. S. Nairne, I. Neath, and A. M. Surprenant (Eds.), The nature of remembering: Essays in honor of Robert G. Crowder (pp. 69-93). Washington, DC: American Psychological Association.

New, B., Pallier, C., Brysbaert, M., \& Ferrand, L. (2004). Lexique 2: A new French lexical database. Behavior Research Methods, Instruments, \& Computers, 36, 516-524.

Notebaert, W., \& Soetens, E. (2003). The influence of irrelevant stimulus changes on stimulus and response repetition effects. Acta Psychologica, 112, 143-156.

Parris, B. A., Dienes, Z., \& Hodgson, T. L. (2012). Temporal constraints of the word blindness posthypnotic suggestion on Stroop task performance. Journal of Experimental Psychology: Human Perception and Performance, 38, 833-837.

Parris, B. A. (2014). Task conflict in the Stroop task: When Stroop interference decreases as Stroop facilitation increases in a low task conflict context. Frontiers in Psychology, 5:1182. doi: 10.3389/fpsyg.2014.01182

Risko, E. F., Schmidt, J. R., \& Besner, D. (2006). Filling a gap in the semantic gradient: Color associates and response set in the Stroop task. Psychonomic Bulletin \& Review, 13, 310-315.

Scheibe, K. E., Shaver, P. R., \& Carrier, S. C. (1967). Color association values and response interference on variants of the Stroop test. Acta Psychologica, 26, 286-95.

Schmidt, J. R., \& Cheesman, J. (2005). Dissociating stimulus-stimulus and response-response effects in the Stroop task. Canadian Journal of Experimental Psychology, 59, 132-138.

Seymour, P. H. (1974). Stroop interference with response, comparison, and encoding stages in sentence-picture comparison task. Memory \& Cognition, 2, 19-26.

Seymour, P. H. (1977). Conceptual encoding and locus of the Stroop effect. Quarterly Journal 
of Experimental Psychology, 29, 245-265.

Sharma, D., \& McKenna, F. P. (1998). Differential components of the manual and vocal Stroop tasks. Memory \& Cognition, 26, 1033-1040.

Stirling, N. (1979).Stroop interference: An input and an output phenomenon. Quarterly Journal of Experimental Psychology, 31, 121-132.

Stroop, J. R. (1935). Studies of interference in serial verbal reactions. Journal of Experimental Psychology, 18, 643-662.

Szücs, D., \& Soltész, F. (2010). Stimulus and response conflict in the color-word Stroop task: a combined electro-myography and event-related potential study. Brain Research, $1325,63-76$.

van Veen, V., \& Carter, C. S. (2005). Separating semantic conflict and response conflict in the Stroop task: A functional MRI study. NeuroImage, 27, 497-504.

White, D., Risko, E. F., \& Besner, D. (2016). The semantic Stroop effect: An ex-Gaussian analysis. Psychonomic Bulletin \& Review.

Zhang, H., \& Kornblum, S. (1998). The effects of stimulus-response mapping and irrelevant stimulus-response and stimulus-stimulus overlap in four-choice Stroop tasks with single-carrier stimuli. Journal of Experimental Psychology: Human Perception and Performance, 24, 3-19. 